\title{
Health in cities: is a systems approach needed?
}

\author{
Saúde nas cidades: precisamos de uma \\ abordagem sistêmica?
}

\author{
Salud en las ciudades: ¿es necesario un \\ enfoque sistémico?
}

\footnotetext{
1 School of Public Health, Drexel University,

Philadelphia, U.S.A.

Correspondence

A. V. Diez Roux

School of Public Health,

Drexel University.

Nesbitt Hall, 3215 Market

St., Philadelphia, PA, 19104,

U.S.A.

avd37@drexel.edu
}

\begin{abstract}
This paper reviews the potential utility of using the concepts and tools of systems to understand and act on health in cities. The basic elements of systems approaches and the links between cities as systems and population health as emerging from the functioning of a system are reviewed. The paper also discusses implications of systems thinking for urban health including the development of dynamic conceptual models, the use of new tools, the integration of data in new ways and the identification of data gaps, and the formulation of different kinds of questions and identification of new policies. The paper concludes with a review of caveats and challenges.
\end{abstract}

Health Inequalities; Social Determinants of Health; Cities; Urban Health

\section{Resumo}

O artigo faz uma revisão da utilidade potencial de conceitos e ferramentas sistêmicos para compreender e agir sobre a saúde urbana. A revisão inclui os elementos básicos das abordagens sistêmicas $e$ os elos entre cidades enquanto sistemas e a saúde da população, a partir do funcionamento de um sistema. A autora também discute as implicações do pensamento sistêmico para a saúde urbana, incluindo o desenvolvimento de modelos conceituais dinâmicos, o uso de novas ferramentas, novas formas de integração de dados e a identificação de lacunas nos dados, e a formulação de tipos diferentes de questões e a identificação políticas novas. O artigo conclui com uma revisão das limitações e desafios.

Desigualdades em Saúde; Determinantes Sociais da Saúde; Cidades; Saúde Urbana 
Levels of urbanization have grown exponentially worldwide. Today over half of the world's population lives in cities, and it is expected that $60 \%$ will live in cities by 2030 1. Urbanization rates in some regions of the world are exceptionally high. For example Northern America is the most urbanized: $82 \%$ of the population lived in urban areas in 2010, and its population is projected to be almost $89 \%$ urban by 2050 . About $79 \%$ of the population of Latin America lived in urban areas in 2010. By the middle of the $21^{\text {st }}$ century Latin America's population is projected to be $87 \%$ urban ${ }^{2}$. As urban populations have grown, the health issues faced by city residents have expanded beyond the traditional urban health concerns linked to infectious diseases and toxic environmental exposures to also encompass chronic diseases linked to poor diets, sedentary life styles, and obesity, as well as physical and mental health issues linked to violence, poverty, and unemployment. In addition, because city residents are often very diverse in race/ethnicity and socioeconomic circumstances, cities typically have large inequalities in health across social groups that are often manifested spatially as pronounced differences in health across neighborhoods. These inequalities are in turn reinforced by important differences across neighborhoods in physical and social environments important to health.

Cities also present enormous opportunities for health improvement There are many examples of the ways in which various urban policies - ranging from the design of cities, to the location of food stores and recreational facilities, to improving access to early childhood education, to the more traditional public health policies of infection control and mitigation of environmental hazards - can have measurable beneficial impacts on health. Despite this potential, urban dwellers continue to experience many adverse health outcomes and large health inequalities. The recent emphasis on multilevel approaches to research and intervention in population health has highlighted the ways in which a range of policies - and more generally many of the ways in which we organize or fail to organize ourselves as a society - can have important health consequences. Although this is no different in urban than in rural areas, cities by force of their sheer density and diversity of population (with consequent environmental and social implications) have always presented unique challenges as well as opportunities to health.

\section{Cities as systems}

There is a long tradition of conceptualizing cities as systems. Early on systems approaches to cities involved objectives like modeling the development, evolution, and decay of cities over time. For example, over 40 years ago, Forrester, often described as one of the founders of system dynamics, used a growth model to generate the life cycle of an urban area from its founding through its decay 250 years later. He also used systems modeling to explore how various policies (related to employment, housing, and industry) might affect the evolution of a depressed city over the next 50 years 3 . More recently, in his book The New Science of Cities, Batty 4 argues that to un derstand cities we must view them as systems of networks and flows, and uses the concepts and tools of complex systems to discuss the structure of cities and how they function.

Although multiple definitions of systems and complex systems exist, key elements of systems include (1) the presence of factors at multiple levels of organization (e.g. city level factors related to governance, neighborhood factors such as environmental or social characteristics, various institutions and their organizational characteristics, families, and individuals); (2) heterogeneous units, be they individuals, institutions, neighborhoods etc.; (3) dependencies between units, e.g. norms being transmitted from person to person or neighborhoods close together in space influencing each other; and (4) positive and negative feedbacks (environmental policies influencing residential segregation and segregation in turn reinforcing environmental policies) 5,6,7. Acting together, these factors and processes result in the emergence of patterns that may not be easily understandable or predictable if one is not cognizant of the functioning of the system as a whole. Arguably, identifying the most appropriate intervention or policy to move the systems in a particular direction or predicting the impact of an intervention or policy can be difficult (or perhaps even impossible) via reductionist approaches that attempt to isolate the effect of a given factor while keeping all others constant. This is because the effect of a given intervention on the system depends on the relationships and state of all other key system components.

\section{Systems thinking in health}

Separately from the long tradition of conceptualizing and modeling cities as systems, there has been increasing interest in applying the concepts and tools of systems thinking and systems analy- 
sis to population health problems 5,6,8,9. Population health in the context of cities is no exception. Systems approaches go beyond the recognition that health is affected by distal factors or factors defined at multiple levels of organization, as has been the tradition in public health for a long time. They explicitly allow for dynamic processes including feedbacks as well as interdependencies and interactions between individuals and between individuals and environments over time. These feedbacks and interdependencies can result in non-linear relations and unanticipated effects distant in space or time. In going beyond the traditional emphasis on isolating the "independent" effect of specific factors to an understanding of the functioning of the system as a whole, the use of systems approaches implies a paradigm shift in the way in which population health is conceptualized, studied, and intervened on.

The study of infectious diseases (because of the contagious nature of many infections) has long embraced and incorporated some features of systems in analytical approaches (such as the need to account for transmission from individual to individual and consequent dependencies), but only recently have systems approaches garnered attention in other areas of health 10,11,12. Two important factors have contributed to this trend. One factor is the increasing frustration with traditional approaches used in population health research, essentially the randomized experiment and the use of observational data to approximate the randomized experiment to the extent possible. Although these strategies have yielded much useful information, there is a sense that they do not allow us to fully understand or identify the best way to act upon many big outstanding questions in health, including key drivers of population health trends and disparities in health across social groups 5,6. It is believed that novel conceptualizations and tools are necessary to transcend impasses in our understanding. A second major factor has been increasing availability of the tools needed to build and simulate appropriate formal models of systems. This has led for example to an explosion of interest in agent-based models, as an accessible and often intuitive approach to systems modeling for the novice 9,13 .

\section{Implications for understanding health in cities}

It is important to consider how the long tradition of studying urban systems and the more recent interest in applying systems approaches to the study of population health problems can be brought together to enhance our understanding of the drivers of health in cities and the plausible impact of various policies and interventions. In considering the utility of systems approaches for the study of urban health it is important to move beyond metaphorical discussions to concrete applications that illustrate the informativeness and utility of systems approaches to answer meaningful questions about the drivers of urban health or the plausible impact of various actions. When used with scientific rigor, systems approaches may yield new insights into old problems, identify new important questions, and point to new kinds of data that need to be collected or processed in order to advance the goal of improving health in cities. But what are some of the specific ways in which systems thinking can transform research and action in urban health?

One major implication of applying systems approaches to urban health problems (perhaps the most important implication) is the development of conceptual models of the processes leading to health in urban settings that explicitly incorporate dynamic relations, i.e. dependencies and feedbacks, as appropriate to the problem at hand. These models must move beyond generic depictions to very specific conceptualizations relevant to a given health problem or research question. The development of these models may involve input from stakeholders as well as scientists as appropriate to the research problem and context. A major challenge in developing these dynamic conceptual models is setting the bounds and including only the elements fundamental to understanding the process at hand. It is important to remember that a systems model (or a complex systems model) is not necessarily a very complicated model. Intelligent abstraction is key if these models are to be useful in advancing knowledge. It is also important to recognize that often many aspects of these models can be investigated using traditional approaches (i.e. formal simulation of a system is not always necessary). The dynamic conceptual model in itself serves to place findings in context regardless of whether formal simulation follows. Moreover, the process of developing these models often starkly illuminates where knowledge about the underlying processes is thin or absent, and points to new directions for inquiry. The knowledge gained about components of the dynamic model using traditional approaches can then be used to refine the conceptual model and inform formal simulation of the system in the future.

A second implication is the need to employ new tools, specifically the development of a formal simulation model that can then be used to explore the functioning of system and the plausible impact of various interventions on the sys- 
tem. Various types of formal simulation models exist including agent-based models and systems dynamic models. These formal models involve the creation of virtual worlds, hopefully informed by empirical data that can then be manipulated to better understand the health implications of the various relations encoded in the model. It is important to emphasize that the extent to which conclusions derived from the model are valid in the real world depends on the extent to which the model appropriately captures the essential processes. The model is not the real world, but merely our effort to mimic how it functions 14 . Therefore, simulation modeling will never replace rigorous observation, although it can help us understand the implications of several observed facts acting in concert.

Third, the use of systems approaches also has implications for the ways we collect and integrate data. By definition, the development of a formal systems simulation model requires integrating various kinds of data, including both qualitative and quantitative data. Meaningful systems models allow us to understand the implications and consequences of various pieces of quantitative and qualitative information in ways that we would not necessarily have predicted if we did not do the formal simulation. This is where the real value of systems modeling lies. In addition the process of conceptualizing the dynamic model and then formalizing the simulation model often leads to the identification of important gaps in data or suggests new questions that can be answered using traditional approaches. The collection of new data and the responses to new questions can also subsequently serve to improve our understanding of how the system works and improve the validity of the simulation model for answering other questions.

Lastly, the use of systems approaches also has implications for the types of questions we ask, and ultimately for the types of policies we can identify as important to improving health in cities. For example, a traditional urban health question might be "Are neighborhood characteristics independently associated with health after accounting for the individual-level socioeconomic position of residents?" whereas the related question that we would answer with a systems approach would be "To what extent (and under what conditions) could residential segregation generate, and reinforce, health disparities by race?" In another example, the traditional question would be "Is proximity to supermarkets (as a proxy for healthy food access) associated with better diet after adjustment for individual-level characteristics of residents?", whereas a more systems oriented question would be "What is the plausible impact on dietary health inequalities of a strategy to subsidize the location of supermarkets in certain areas under various spatial patterning scenarios?" 10 . These different kinds of questions allow for the possibility not only of directly assessing the plausible impact of various policies but also of identifying potentially useful policies that we might not have imagined (or identified as relevant) before performing the simulation modeling. Here the emphasis on "plausible" and "potential" is key, because as we have noted, the model only allows us to identify implications of an action under the set of conditions encoded in the model. Often the insights obtained from simulation modeling still need to be tested in the real world.

\section{Caveats and conclusion}

Current interest in systems thinking in population health presents important opportunities for creative thinking in the area of urban health. Aside from the crucial factor of encouraging the development of dynamic conceptual models of health in cities, systems approaches provide us with new analytical tools (specifically simulation modeling) that can be used to enhance insight and identify new areas for additional exploration using a range of analytical approaches. Systems thinking also provides formalized ways for urban health researchers to link to other disciplines interested in the functioning of cities and allows input from various stakeholders and communities in the formulation of conceptual models and in the interpretation of results of simulation modeling. However, in order to be truly transformative these new approaches need to be employed to answer very specific questions and yield new insights. Moving beyond metaphorical discussions of urban systems to concrete applications that yield new information will be essential. At their best, the use of systems approaches will allow us to see and understand patterns and trends that researchers, communities, and policymakers may not otherwise be aware of. They may also allow us to identify the best ways to modify these patterns. Training in these approaches and the development of exemplar applications will be important. Identification of specific types of situations in which systems approaches may be most useful will also be valuable. Systems approaches will never replace traditional quantitative and qualitative empirical approaches in urban health research, but if integrated with other strategies, they may help advance our understanding of the determinants of urban health as well as enhance our ability to intervene to improve health and reduce health inequalities in urban settings. 


\section{Resumen}

Este trabajo analiza las posibilidades de uso de los conceptos e instrumentos de la teoría de sistemas para entender y actuar en el ámbito de la salud urbana. Se revisan los elementos básicos del enfoque sistémico y los vínculos entre las ciudades como sistemas y la salud poblacional como fenómeno emergente del funcionamiento del sistema. Se discuten también las implicaciones del pensamiento sistémico para la salud urbana incluyendo la elaboración de modelos dinámicos conceptuales, el uso de nuevos instrumentos, la integración innovadora de los datos, la identificación de carencias de información, el planteamiento de problemáticas nuevas y la elaboración de nuevas políticas. El artículo concluye con una reflexión sobre las dificultades y problemas que todo ello plantea.

Desigualdades en la Salud; Determinantes Sociales de la Salud; Ciudades; Salud Urbana

\section{References}

1. World Health Organization. Urban population growth. http://www.who.int/gho/urban_health/ situation_trends/urban_population_growth_text/ en/.

2. Population Division, Department of Economic and Social Affairs, United Nations. World urbanization prospects, the 2011 revision. New York: United Nations; 2012.

3. Forrester J. Urban dynamics. Boston: Pegasus Communications; 1969.

4. Batty M. The new science of cities. Boston: MIT Press; 2014

5. Galea S, Hall C, Kaplan GA. Social epidemiology and complex system dynamic modelling as applied to health behaviour and drug use research. Int J Drug Policy 2009; 20:209-16.

6. Diez Roux AV. Complex systems thinking and current impasses in health disparities research. Am J Public Health 2011; 101:1627-34.

7. Sterman JD. Learning from evidence in a complex world. Am J Public Health 2006; 96:505-14.

8. Pearce N, Merletti F. Complexity, simplicity, and epidemiology. Int J Epidemiol 2006; 35:515-9.
9. Auchincloss AH, Diez Roux AV. A new tool for epidemiology: the usefulness of dynamic-agent models in understanding place effects on health. Amn J Epidemiol 2008; 168:1-8.

10. Auchincloss AH, Riolo RL, Brown DG, Cook J, Diez Roux AV. An agent-based model of income inequalities in diet in the context of residential segregation. Am J Prev Med 2011; 40:303-11.

11. Yang Y, Diez Roux AV, Auchincloss AH, Rodriguez DA, Brown DG. A spatial agent-based model for the simulation of adults' daily walking within a city. Am J Prev Med 2011; 40:353-61.

12. Cerda M, Tracy M, Ahern J, Galea S. Addressing population health and health inequalities: the role of fundamental causes. Am J Public Health 2014; 104 Suppl 4:S609-19.

13. Marshall BDL, Galea S. Formalizing the role of agent-based modeling in causal inference and epidemiology. Am J Epidemiol 2015; 181:92-9.

14. Diez Roux A. The virtual epidemiologist: promise and peril. Am J Epidemiol 2015; 181:100-2.

Submitted on $07 /$ Nov/2014

Approved on 19/Nov/2014 


\section{Debate on the paper by Diez Roux Debate sobre o artigo de Diez Roux \\ Debate acerca del artículo de Diez Roux}

http://dx.doi.org/10.1590/0102-311XCO01S115

Gérard Salem

Laboratorie Dynamiques Sociales et Recomposition des Espaces, Université Paris Ouest,

Nanterre, France. salem.gerard@gmail.com

\section{A systemic approach to urban health: why, how, and what for?}

Diez Roux's paper is interesting in many ways, characterized with "opened questions" more than "authoritative proposals" (as we often encounter). She explains in clear and illustrated terms the relevance of adopting a systemic approach to "urban health" in order to understand the complexity of the relationship between urban space, ways of life and health. Sharing Diez Roux's point of view, I wish to briefly present three sets of additional questions.

\section{A systemic approach: why?}

A systemic approach could be a way to overcome the limits of "risk factor epidemiology", even if researchers have paid attention to multi-factorial determinants and multi-scale understanding of contextual and local determinants of health. Classical epidemiology can describe health changes, health dynamics, and spatial and social health inequalities, but cannot analyze the social and environmental process involved in the production of these situations. A systemic approach could highlight the complexity of the interrelations, interactions, and retroactions that characterize urban health.

\section{A systemic approach: how?}

However, is a systemic approach able to provide (by construction) an understanding of the processes at the origin of urban health dynamics or urban health inequalities? The word "approach" is original: is it a concept? A method? A tool? Beyond a naïve "natural interdisciplinary point of view", is it possible to adopt a systemic approach without hypothesis (and of course an explicit hypothesis: we know, as does Popper, that when a hypothesis is not explicit, it is implicit and irrefutable...). Ana Diez Roux offers concrete research methods, including a controlled hypothesis based on which a systemic approach could be developed, but on very well-defined and con- trolled research questions... not so different from what researchers are used to do.

A systemic approach to urban health could be a way to understand the interrelations between two complex systems: Cities and Health. It could be (and it should be!) an opportunity to bridge the gap between these two spheres. First, we would need to define:

(i) What is "urban" (size, characteristics, limits/ physical, economic, social, and cultural characteristics) and what would be an "urban system", considering health issues. While experts in urbanism and urban planning define these concepts differently according to their research questions, their categories (legal versus illegal, center versus periphery, etc.) are not always relevant to health. (ii) What is "health" (not only diseases, causes of death, etc.) and a "health system" (not only the healthcare system), and what are the specificities of health in the urban context? Health experts have no global or definitive definition and have no clear ideas on the impact of quality of health on urban systems, or the impact of the healthcare system's organization and activities on urban system dynamics.

(iii) What is the complex interface between "Cities" and "Health"? We still do not really know how to look at cities in terms of health. A factor such as high population density could be a relevant risk factor in some cases (TB, measles) and a protective factor in others (malaria). Living in a peripheral settlement provides an opportunity for better access to fresh food but acts as a handicap for accessing the healthcare system. We still do not know how to analyze the interrelations between urban dynamics and health changes, e.g. how urban segregation impacts health inequalities, or how the population's health status (premature death, avertable morbidity) impacts urban dynamics.

\section{A systemic approach: what for?}

A systemic approach could help decision-makers, because such a global approach highlights the interdependence between urban planning and public health and underlines the need for an inter-sectoral approach to health determinants and an assessment of consequences of each urban management decision on health (even its unintentional consequences).

Still, doesn't this "ecumenist" approach run the risk of an ahistorical and apolitical understanding of the real stakes in urban health, social and territorial inequalities (e.g. social domination and segregation), and different actors' strategies to deal with the city and public health? 
http://dx.doi.org/10.1590/0102-311XCO02S115

\section{Paulo Saldiva}

Faculdade de Medicina, Universidade de São Paulo, São Paulo, Brasil. Instituto Nacional de Análise Integrada do Risco Ambiental, São Paulo, Brasil. pepino@usp.br

\section{Nilmara de Oliveira Alves}

Faculdade de Medicina, Universidade de São Paulo, São Paulo, Brasil. nilmaraoalves@gmail.com

\section{Mariana Veras}

Faculdade de Medicina Universidade de São Paulo, São Paulo, Brasil. Instituto Nacional de Análise Integrada do Risco Ambiental, São Paulo, Brasil. verasine@gmail.com

\section{Addressing the complexity of urban living: a new opportunity to improve public health}

The paper by Diez Roux addresses the need to employ a systemic approach to understand urban health determinants, a basic condition for creating solid and positive public health policies. Cities are increasingly becoming human beings' natural habitat. Throughout history, urban living was consistently associated with adverse health conditions. Poor sanitation in crowded human settlements provided the perfect scenario for the development of cholera and other enteric diseases. In cities, yellow fever, smallpox, and bubonic plague killed millions of people. Cities also created the conditions for modern epidemiology after John Snow controlled a cholera outbreak in London by closing down a public water well 1 . Thus, cities have long demanded an ecosystem approach to improve public health, mostly focused on infectious diseases. Today's cities face new health problems, since chronic non-communicable diseases are more prevalent in urban areas and are modified by them. Mental illness, obesity, diabetes, cardiovascular disease, and cancer all display an urban-rural risk gradient 2,3,4. To address these questions, health professionals are again facing the need to think and plan actions based on ecosystem premises. In fact, health should be considered a primary delineator of urban development and management, and health professionals must engage in the process of adding to Plato's utopian ideal city based on politics, ethics, and social relations, a fourth parameter: human health 5,6.

Worldwide, nearly 17.5 million people die per year from cardiovascular diseases 7 . Chronic non-communicable diseases have multiple factors (genetic, epigenetic, behavioral, and environmental). In this context, conditions that are more frequent in the urban setting such as air pollution, social stress, and climate changes (heat islands, for instance) should be considered important health determinants and included in the policymaking and planning process to effectively contribute to health promotion at all social levels.

Urban agglomerates are responsible for a large share of pollutants. To understand the urban process, we must view cities not simply as places in space but as systems of networks and flows. The "human ecology" concept includes a systems-based approach that enables an integrated view of the urban environment and public health 8,9
According to William Rouse 10, the Earth is reflected as a collection of different systems on different scales: environment, population, industry, and government (Figure 1).

Let us explore, for example, the possible paths by which urban living contributes to cardiovascular disease. Cities experienced social and technological changes that ultimately created a dominant human habitat: long time spent in traffic, long working hours, airborne pollutants, stress, and easy access to high-fat/high-sugar/highsodium foods combined with sedentary lifestyle and poor eating habits. These factors contribute directly or indirectly (by modifying) the risks of heart diseases.

From this perspective, air pollution has become part of modern living, and exposures are associated with numerous manifestations of heart disease, indicating that it not only exacerbates existing heart conditions but also appears to play a role in the development of diseases 11 . Air pollution ranks ninth among modifiable disease risk factors, and the risk of air pollution exceeds other well-known risk factors such as physical inactivity, high-sodium diet, high cholesterol, and drug use.

Moreover, the intensification of weather and climate extremes, the most visible impact of global warming on our everyday lives, can contribute to increasing the incidence of myocardial infarction, especially in the elderly 12,13 .

Thus, in order to reduce the prevalence of cardiovascular disease, health professionals should face the complexity of the urban system, which encompasses factors not usually viewed as health determinants, such as urban planning, public transportation, and fuel policies. Other simulations could be developed for cancer, obesity, and diabetes, conditions influenced significantly by urban living.

Importantly, different factors (social, behavioral, physiological, environmental, psychological, and lifestyle) interact to determine and affect the health status of individuals and communities in a way that allows many opportunities for positive health interventions, for example, e.g. different public polices for the environment, transportation, and energy generation. This complexity of the urban scenario creates both challenges and opportunities. Diez Roux invites us as health professionals to incorporate a broader and more integrated approach when addressing health problems, so that her article is both timely and necessary. 
A systems approach to cities includes four key elements: environment, population, industry, and government. Acting together, this approach allows an integrated view of direct and indirect health impacts.

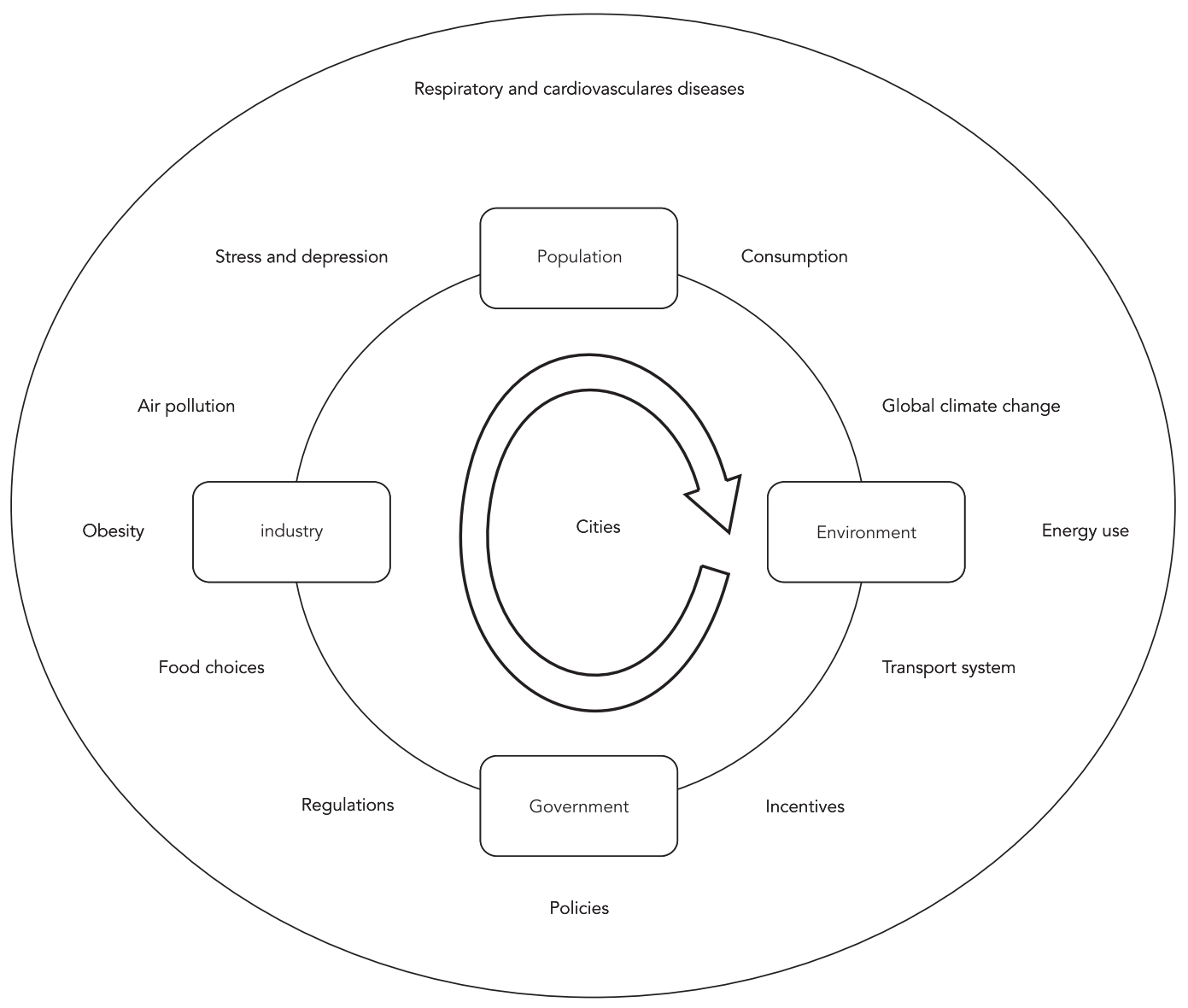

1. Paneth N. Assessing the contributions of John Snow to epidemiology: 150 years after removal of the Broad Street pump handle. Epidemiology 2004; 15:514-6.

2. World Health Organization. Global status report on noncommunicable diseases 2010: description of the global burden of NCDs, their risk factors and determinants. Geneva: World Health Organization; 2011.

3. Monroe AC, Ricketts TC, Savitz LA. Cancer in rural versus urban populations: a review. J Rural Health 1992; 8:212-20.

4. Barker DJP. Fetal origins of coronary heart disease. BMJ 1995; 311:171-4.

5. Anstey MHR. Climate change and health: what's the problem? Global Health 2013; 9:4.
6. Bezirtzoglou C, Dekas K, Charvalos E. Climate changes, environment and infection: facts, scenarios and growing awareness from the public health community within Europe. Anaerobe 2011; 17:337-40.

7. World Health Organization. Global status report on noncommunicable diseases 2014. Geneva: World Health Organization; 2014.

8. Fleming ML, Tenkate T, Gould T. Ecological sustainability: what role for public health education? Int J Environ Res Public Health 2009; 6:2028-40.

9. McMichael AJ. Will considerations of environmental sustainability revitalise the policy links between the urban environment and health? N S W Public Health Bull 2007; 18:41-5. 
10. Rouse W. Earth as a system. In: National Research Council, editor. Can Earth's and society's systems meet the needs of 10 billion people? Washington DC: The National Academies Press; 2014. p. 20-3.

11. Newby DE, Mannucci PM, Tell GS, Baccarelli AA, Brook RD, Donaldson K, et al. Expert position paper on air pollution and cardiovascular disease. Eur Heart J 2015; 36:83-93b.

12. Guerrero-Bosagna C, Jensen P. Globalization, climate change, and transgenerational epigenetic inheritance: will our descendants be at risk? Clin Epigenetics 2015; 7:8.

13. Madrigano J, Mittleman MA, Baccarelli A, Goldberg R, Melly S, von Klot S, et al. Temperature, myocardial infarction, and mortality: effect modification by individual- and area-level characteristics. Epidemiology 2013; 24:439-46.

http://dx.doi.org/10.1590/0102-311XCO03S115

\section{Sandro Galea}

School of Public Health, Boston University, Boston, U.S.A. sgalea@bu.edu
Professor Diez Roux brings together two relatively recent traditions in population health science scholarship - an explicit focus on the health of urban populations as an area of discrete inquiry, and the adoption of complex systems approaches to articulate, and hopefully answer, questions of import for population health. Professor Diez Roux makes a case for the potential utility of systems methods to the study of urban health and articulates four implications that might emerge through a marriage of systems science and urban health scholarship. I generally agree with the argument presented by Professor Diez Roux, and highlight here two additional thoughts that may extend the argument, perhaps provoking further discussion in the field.

In many respects all of science is concerned with the articulation of appropriate metaphors that help our understanding of the world. These metaphors are typically reductionist, replacing complex webs of causation with simpler ideas that allow the articulation of hypotheses that are testable using available tools. Some disciplines have the luxury of articulating questions that can be shorn of context, and that, as such, can be shown to produce the same knowledge when repeated time and time again, under the same conditions. Physics comes to mind as the classic example in this case. The same perfectly spherical ball in the same vacuum will be expected to always react in the same way to an equivalent force applied to it. Clearly in real life we do not have many dealings with perfectly spherical balls in vacuums, but experiments under controlled conditions provide us with insights that we can then learn from and extend to the far messier situations under which we typically deal with moving objects. In this case, a simplifying metaphor allows the formulation of universal properties that inform our understanding of the natural world. Other disciplines, however, deal with an intractably complex set of causes that may make overly reductionist metaphors inefficient and unhelpful. If we are interested in how spatial residential segregation generates racial disparities in health, we are likely to learn little about this phenomenon from studying any two individuals and how they interact with one another.

This is the central challenge faced by population health in general, and by urban health in particular. We are interested in answering questions that are, of necessity, dependent on their context and that benefit only in a limited way from simplification. This challenge bedevils inference that rests on assumptions about the plausibility, and utility, of causal isolation, controlling for the influence of context. To this end, the adoption of systems thinking in urban health stands to make a contribution, centrally through forcing the articulation of tractable metaphors at a level of complexity that can be useful to advancing our understanding. Systems approaches require the explicit conceptualization of models that can serve as the starting point of our analytic efforts. Drawing of these models, physically or conceptually, is, in many ways, much harder than are the technical aspects of model building, or even the arduous task of model specification. The model explication process requires us to ask which factors might matter, how they interact, and what the underlying causal architecture that produces health might be. Requiring scientists to articulate a model forces us to be clear about the guiding metaphor we are using to ask our questions, and, as such, how we should be going about looking for answers. This stands to be the central contribution of systems approaches to urban health inquiry. Urban health is motivated by a desire to understand how dense, diverse, and increasingly ubiquitous human-made environments influence health. It is intuitive that these environments influence the air their residents breathe, water they drink, food they eat, and how urban residents feel, think, and behave. However, from the perspective of framing urban health questions of consequence, we need to understand what in these urban environments influences health within this complex context. This requires the scientist to articulate useful metaphors, and complex systems approaches stand to be a tool to get us there, perhaps rising in utility 
above the other benefits systems approaches can bring to urban health inquiry.

Professor Diez Roux's comments, focusing on the adoption of systems methods in urban health inquiry, aim to introduce the relevance of these ideas to a broader audience. There is little question that the field of urban health specifically, and public health more broadly, remains quite far from the widespread adoption of systems thinking. Our mainstream training, scholarship, and practice of urban health remains centered explicitly on causal paradigms that suggest we can effectively isolate causes that are instrumental in the production of health. This leads a quest for singular causes that can serve as levers we may manipulate to improve the health of these populations. But is this approach even realistic? Should systems thinking be (as it is now) a "new" approach on the margins of the field, which needs special commentaries to gain acceptance and a foothold in the mainstream of the science? Or should we accept that we are dealing with irreducibly complex systems, and that we need to be in the business of articulating metaphors that grapple with this complexity, grounded in the approaches of systems thinking? Systems thinking is late to the game in population health, emerging only recently in empirical discussions in the field. This reflects the dominant deterministic paradigms that have long dominated thinking in the health sciences, and the dominant pedagogical paradigms that continue to guide our training programs. Professor Diez Roux suggests that systems approaches will never replace more traditional empirical approaches in urban health research. But, one wonders, should they? Traditional empirical approaches are predicated on the assumption that we can articulate simplifying metaphors to the end of generating knowledge that is durable and applicable across contexts. Hence, we can understand the physics of motion of a spherical object in a vacuum, and those observations always hold. But that is worlds away from the questions of interest in urban health. Urban health is ultimately interested in questions that are irrevocably contextual. The very field, concerned with the nature of the urban environment, rests on the understanding of particular contexts that are far too complex to distill into overly simplifying metaphors. One can imagine a body of scholarship that is predicated on an embrace of complexity, where the adoption of approaches in systems science underlies the questions we ask and the answers we seek, and frames how we teach our students. This does not have to mean that the methods of systems science - be they differential equations models or autonomous agent-based models - need to

be applied to all urban health questions. It does mean however that the concepts of systems thinking would take precedence in framing our thoughts, in shaping our metaphors, and in guiding the questions we ask. That would be a very different urban health scholarship than the one we have today. Professor Diez Roux's comments provide an early nudge in this direction.

http://dx.doi.org/10.1590/0102-311XCO04S115

\section{Carlos Dora}

Department of Public Health Environmental and Social Determinants of Health, World Health Organization, Geneva Switzerland. dorac@who.int

\section{Systems approaches could provide a better understanding of urban health determinants and inform interventions. What are the next steps in delivering this promise?}

Diez Roux presents in this Supplement of Cadernos de Saúde Pública a clear argument for why systems theory should be instrumental for understanding the root causes of urban health and for tackling ill health and inequalities in cities. I am persuaded by the ways in which systems theory can help transform research and action for urban health, as she proposes. She focuses particularly on the development of conceptual dynamic models of the processes leading to health in urban settings, drawing on inputs from researchers and stakeholders, which in turn draw on scientific knowledge and contextual/local factors, while mapping out expected feedback loops and dependencies. These conceptual models are essential for clarifying/generating hypotheses about linkages between health and the urban environment and for identifying potential interventions and their expected impacts on health.

The second mechanism she proposes is simulation modelling of such relations to examine expected impacts from interventions, considering possible pathways and feedback loops. The creation of these "virtual worlds" is both attractive and tantalizing, in that the more complexity one adds to the model, the greater the possibilities of error and eventual misunderstanding of the systemic effects. This also raises a number of questions, including who sets the parameters, which aspects are included in the model and which are left out, various hierarchies, and how one considers conflicting interests in the absence of consensus. On the other hand there is an opportunity to learn from the experience in cities worldwide 
regarding their decisions and implementation of policies on similar issues, such as transportation, housing, land use planning, and energy, all of which have important health implications. But again, it is essential to define the knowledge management parameters to attempt to avoid biases in reporting and publication, among others, and the methods used to summarize large amounts of natural experiments occurring in different settings, to identify both good and bad practices. Practical questions also include how to link different types of data, the use of "big data" 1 , available tools for integrating different types of datasets, and lessons from previous attempts to develop large integrated models (such as those used to estimate the impacts of transportation policies on health 2). Researchers interested in further development of this field feel the need to hear more about the state-of-the-art and existing wisdom on these questions.

The author's third point is very well taken: there is a need to focus on very specific questions and to move from metaphorical discussions of urban systems to concrete applications. Stakeholder interests, scientific knowledge, policymaking, and decision-making are centered on specific questions and options, and often there is a failure to appreciate their systemic effects. Health is crosscutting and can be used as a common denominator/entry point to clarify the nexus between different policy decisions in the urban setting.

The paper by Diez Roux raises elements for what could become a global research and action agenda for determinants of urban health. This agenda should be pursued in order to provide the tools and capacity to help visualize change and to explore policy alternatives and their expected consequences for health and quality of life and their comparative potential for achieving greater equity. The outcome of this agenda would include a knowledge base, tools, and capacity for robust analyses of urban policy scenarios that lead to the greatest shared health benefits and to other urban policy objectives. Implementing such a research agenda would add powerful tools for health actors to engage in (and contribute to) debates on urban policies and decisions and enable the health sector to expand its contribution to global sustainability and health equity.

This would not only contribute to mainstreaming health into the Sustainable Development Goals (SDGs) ${ }^{3}$ and the HABITAT III ${ }^{4}$ agendas but also constitute an extra tool for pursuing health in all policies.

\section{Disclaimer}

The above review was written by an employee of the World Health Organization, but the statements, opinions, and conclusions do not represent official WHO policies or positions.

1. Khoury MJ, Ioannidis JPA. Big data meets public health. Science 2014; 346:1054-5.

2. Integrated Environmental Health Impact Assessment System. http://www.integrated-assessment. eu/ (accessed on 20/Apr/2015).

3. Dora C, Haines A, Balbus J, Fletcher E, Adair-Rohani $\mathrm{H}$, Alabaster G, et al. Indicators linking health and sustainability in the post-2015 development agenda. Lancet 2015; 385:380-91.

4. United Nations Conference on Housing and Sustainable Urban Development, as decided by UN General Assembly Resolutions 66/207, 67/216 and 69/226. http://unhabitat.org/habitat-iii-confer ence/ (accessed on 20/Apr/2015).

http://dx.doi.org/10.1590/0102-311XCO05S115

Marilia Sá Carvalho

Programa de Computação Científica, Fundação Oswaldo Cruz, Rio de Janeiro, Brasil. mariliasaca@gmail.com

\section{Changing the trend: a systems approach to complex urban population health}

The paper by Ana V. Diez Roux brings an important realization to the surface: as researchers using counterfactual approaches to understand disease causality, many of us are totally unhappy with the end results of all the energy applied to "isolating the 'independent' effect of specific factors", very limited in dealing with the main public health problems in such complex settings as cities and megalopolises. Obesity, cardiovascular disease, and diabetes, the main health problems in most urban populations, are resistant to public health interventions, despite our in-depth knowledge of numerous factors, ranging from the cellular level to socioeconomic determinants 1,2 . It is high time we acknowledge the limits of some of our favorite tools in order to bring something new to the research, in the hopes of discovering how, where, when, and which interventions can change the trend.

Systems thinking brings new breath to the recognition that in urban health we are not dealing with isolated factors that add up to cause disease, but as summarized by Ana, as an intrinsically complex situation with multiple levels of organization, heterogeneity, dependencies, and 
feedback. Related to (and as a consequence of) this complexity, I would explicitly include dynamic stability in the description of complex systems' characteristics 3 , as one of the main aspects of unmovable disease trends cited above. Related to the same dynamic stability and inherent complexity, applying pressure at the right points - fulcrums - can bring down a complex system. Exploring scenarios based on either agent-based or full-fledged dynamic models is certainly a powerful tool for finding such fulcrums.

The paper emphasizes an important point in using such techniques: "A major challenge in developing these dynamic conceptual models is setting the bounds and including only the elements fundamental to understanding the process at hand". Any mathematical or statistical model is limited to a few components. Simplification is not merely an option, but an absolute imperative. Thus, what is the gain in this approach if we are still constrained by very limited simulations? I think that the answer lies in the paper as well. The "systems approaches to urban health problems (perhaps the most important implication) is the development of conceptual models of the processes..." I agree entirely, without the parenthesis, and not as "perhaps", but certainly. The orthodoxy in approaching all epidemiological problems by looking for "isolating" and "controlling” measures of association has produced a conservative way of thinking, thereby limiting scientific creativity. And I must say that scientific rigor is not exclusive to mathematical or other quantitative approaches.

Take obesity as an example. We need to be bold enough to include all aspects besides individual and neighborhood characteristics, such as green spaces or food availability. Not excluding those, of course, but including other main players such as the food industry and its ultra-processed foods, soft drink advertising that sells happiness, and externalization of costs from the resulting obesity to the entire society. All of those have been tackled in one paper or another. Integrating all this knowledge to devise a comprehensive intervention is what we need in these times of millions of articles published every year. Rigorously designing this system may allow us to: (i) devise studies addressing specific questions, (ii) chose appropriate parts of the system for computational, dynamic, or statistical models, and (iii) propose public health interventions 4 . However, building such a model is extremely difficult. Our training as epidemiologists is limited, and we do not usually access the literature from cybernetics and systems thinking. Besides, changing our approach to a scientific problem can be as hard as exercising or dieting 5 .
The main advantage of this approach is "bringing action back to epidemiology", placing the improvement of population health in complex urban settings at the center of our collective thinking ${ }^{6}$. Admitting complexity (and perplexity). The challenge is to build bridges between researchers and policymakers, between public health and city planning, changing the question from "what is the isolated effect?" to "what for?" Just asking ourselves which actions are possible, involving from the beginning the people in charge of making it all possible, will highlight the theoretical system's limits, one of the challenges identified in the paper. We truly need to address the deep meaning of the systems approach, and not merely replace one technique with another. I see it as a paradigm shift. Thanks, Ana, for sharing such powerful ideas again.

1. Blomain ES, Dirhan DA, Valentino MA, Kim GW, Waldman SA. Mechanisms of weight regain following weight loss. ISRN Obes 2013; 2013:210524.

2. Avenell A, Broom J, Brown TJ, Poobalan A, Aucott L, Stearns SC, et al. Systematic review of the long-term effects and economic consequences of treatments for obesity and implications for health improvement. Health Technol Assess 2004; 8:iii-iv, 1-182.

3. Abdel-Hamid TK. Thinking in circles about obesity applying systems thinking to weight management. New York: Springer; 2009.

4. Vandenbroeck P, Groossens J, Clemens M. Tackling obesities: future choices - building the obesity system map. https://www.bis.gov.uk/assets/bispartners/foresight/docs/obesity/obesity_final_part1. pdf (accessed on 29/Aug/2013).

5. Valerdi R, Rouse WB. When systems thinking is not a natural act. http://ieeexplore.ieee.org/lpdocs/ epic03/wrapper.htm?arnumber $=5482446$ (acces sed on 12/Dec/2014).

6. Galea S. An argument for a consequentialist epidemiology. Am J Epidemiol 2013; 178:1185-91. 
http://dx.doi.org/10.1590/0102-311XCO06S115

\section{Anthony Capon}

International Institute for Global Health, United Nations University, Kuala Lumpur, Malaysia.

tony.capon@unu.edu

José Siri

International Institute for Global Health, United Nations University, Kuala Lumpur, Malaysia.

siri@unu.edu
Diez Roux makes a compelling case for the value of systems approaches in understanding and responding to contemporary urban health challenges. Although there is a long tradition of systems modeling in infectious disease, we are still in the early days of the application of such approaches to urban health, and indeed to population health more generally. The author argues cogently that the characteristic capacity of systems approaches to account for positive and negative feedback is critical in this context. Systems analytical methods, moreover, are entirely consistent with inter-sectoral approaches, which are already widely accepted as fundamental for effective public health research and action.

Without a systems approach, encompassing both analytical methods and the co-production of knowledge among academics and with lay professionals and communities, researchers and policymakers may struggle to move beyond a siloed approach to the challenges of health and development. An instructive case is transportation by electric automobiles in cities. Around the world, environmentalists are currently advocating for transition of the global motor fleet to electric fuel as a strategy to reduce greenhouse gas emissions and mitigate climate change. However, a switch from fossil-fuel powered cars to electric cars would do nothing to increase active transportation and reduce the sedentary habits that - together with poor nutritional habits - are driving global epidemics of obesity and related non-communicable diseases. It would also fail to change the allocation of space in cities by reducing the amount of land for roads and parking for personal vehicles (which sit unused much of the time) or improving housing location in relation to other resources. It would fail to reduce congestion or stress associated with driving, or free up land for public green space, which has proven health and environmental benefits 1 . In most cases public mass transit and improve conditions for walking and cycling are the best options for healthy and sustainable urban transportation.

The global urban transition is arguably the most profound change in human ecology in the history of human life on Earth 2. In this context, systems approaches are helpful for framing ecosocial understandings of health. The UN system is currently negotiating a new global sustainable development framework for the period 20162030. For the first time, this so-called Post-2015 Development Agenda will integrate the current development focus on poverty eradication with sustainable development. This new develop- ment framework will require new ways of working, including integrative and interdisciplinary approaches to building new knowledge. While systems approaches are not the only way to deliver this, they are one way to do so.

Indeed, it has been argued that there is a pressing need for a new public health paradigm that brings ecological determinants of health more sharply into focus, alongside the social determinants of health. Called "planetary health" 3 , this new paradigm will require public health workers to embrace human ecological understandings, including of the human place in nature and broad relationships between human health and the health of ecosystems, in which the physical structures of cities are understood as artefacts of human activity. All human activities (shaped in turn by the built environments we create) have potential for positive and negative impacts on human health and the health of planetary systems (e.g. the climate system, biodiversity). Systems approaches provide an effective way of understanding the dynamic interplay between the health of people, places, and planetary systems - a human ecological understanding 4 .

In the classic book Thinking in Systems: A Primer, Meadows 5 highlights system traps and opportunities including policy resistance, in which various actors trying to pull a system state toward different goals simply pull the system farther from the goals of other actors and produce additional resistance. In the public health context, this understanding is relevant to the seemingly inexorable increase in obesity rates around the world (despite considerable efforts at prevention and control) and in many other intractable health challenges. A key challenge for effective public health action in cities is to carefully evaluate interventions for potential unintended harmful consequences (e.g., the history of failed grand urban housing schemes to address socioeconomic disadvantage).

Last December, the new International Council for Science (ICSU) 10-year global interdisciplinary urban health program 6 , co-sponsored by the United Nations University and the InterAcademy Medical Panel, was launched with an expert workshop at the Institute of Urban Environment of the Chinese Academy of Sciences in Xiamen. The program aims to convene scientists and their counterparts in government, industry, and communities to tackle critical urban policy and planning questions. The new program will strive for co-production of knowledge to improve decision-making - an approach that acknowledges the expertise of those who make decisions on a daily basis, seeking new insights through 
effective applied research. Here again, systems approaches are indispensable. For example, one such approach - collaborative conceptual modelling (CCM) 7 - provides a structured method for transdisciplinary dialogue, an essential precursor for co-production of knowledge. CCM is a systematic way to bridge differences in language and ways of understanding across sectors, and to bring lay and local knowledge together with understandings from the natural and social sciences and the humanities.

In short, there is no doubt that classical empirical approaches in epidemiology will always remain essential tools for urban health. However, as we confront an array of new urban problems in health - and, no less, in the sustainability of human civilizations - there is a need to embrace both fresh methodological approaches and a broad engagement among unlikely partners, both in science and in the wider world. It remains to be seen whether the promise of systems approaches in urban health will be fulfilled. There is also no doubt that new research funding and further capacity-building will be prerequisites for success.

1. Dannenberg AL, Frumkin H, Jackson RJ. Making healthy places: designing and building for health, wellbeing and sustainability. Washington DC: Island Press; 2011

2. McMichael AJ. The urban environment and health in a world of increasing globalization: issues for developing countries. Bull World Health Organ 2000; 78:1117-26.

3. Horton R. Offline: planetary health - a new vision for the post-2015 era. Lancet 2013; 382:1012.

4. Dyball R, Newell B. Understanding human ecology: a systems approach to sustainability. New York: Routledge; 2014.

5. Meadows DH. Thinking in systems: a primer. London: Earthscan ; 2008

6. Bai X, Nath I, Capon A, Hasan N, Jaron D. Health and wellbeing in the changing urban environment: complex challenges, scientific responses, and the way forward. Curr Opin Environ Sustainability 2012; 4:465-72.

7. Proust K, Newell B, Brown H, Capon A, Browne C, Burton A, et al. Human health and climate change: leverage points for adaptation in urban environments. Int J Environ Res Public Health 2012; 9:2134-58.

\section{The author replies}

A autora responde

La autora responde

http://dx.doi.org/10.1590/0102-311XCO07S115

Ana V. Diez Roux

The insightful comments by Salem, Saldiva et al., Galea, Dora, Carvalho and Capon \& Siri highlight several important points that are worth our reflection as we consider the utility of systems thinking and the tools of simulation modeling in urban health.

Several commentators emphasize the value of systems thinking as a conceptual approach that extends well beyond the use of specific systems simulation tools. Salem challenges us to use systems thinking to better understand the processes (often rooted in social, economic, historic, and political conditions) that shape health and health inequalities in cities. He also highlights how systems thinking forces us to be more deliberate and specific in our definition of "urban" (and what it means to live in urban areas) and also to grapple with the inherent complexity in understanding health-related processes. Galea also notes that the main value in systems approaches is likely to lie in how we conceptualize health determinants and articulate how they operate together to affect health in cities, with special attention to context dependency. Carvalho emphasizes the development of dynamic conceptual models that integrate very different types of factors and processes as the key benefit and value of a systems approach. Capon \& Siri challenge us to think broadly and develop dynamic conceptual models not only of health in cities but also models that articulate the interrelations between human health and ecosystems more broadly.

An important element of the use of systems approaches is the ability to incorporate and integrate various types of information (as noted by Carvalho) and also community and stakeholder input, enhancing co-production of knowledge (as alluded to by Capon \& Siri and Dora). But these approaches also raise many challenges and necessarily highlight the many limitations of the information and data available, as noted by Dora. Ideally, this will stimulate the design of new studies and the collection of new data to fill many gaps in understanding that are likely to emerge as we develop conceptual systems models and begin to attempt their formal simulation. 
Examples are critical to understanding the potential of systems thinking and analytical approaches in urban health. Several commentators provide valuable examples. Saldiva et al. illustrate how systems approaches can be used to understand the drivers of cardiovascular disease in urban areas. Capon \& Siri use the example of the health and ecological consequences of promoting electric cars as an example of a policy for which systems thinking may yield useful insights. They note the value of systems thinking in fully understanding why interventions have not worked as expected or why attempts to stem health trends like the obesity epidemic have been largely disappointing. Dora challenges us to use these approaches to answer relevant policy questions and provide useful evidence for policymakers and communities as they evaluate alternative strategies and policies to improve health in cities.

An important theme that arises in several of the commentaries is whether the advent of systems thinking and systems approaches will or should replace the other analytical tools we use to understand the drivers of health in cities or to evaluate the impact of policies and interventions. Certainly I agree with Carvalho when she notes that fully embracing systems thinking will be a paradigm shift in the sense that it will challenge the reductionist and often biomedical paradigm still dominating the vast majority of health research. However, as Carvalho also notes, simplification is imperative in science, even in the face of complexity. But the simplification required for the simulation of systems is very different from the simplification we engage in when we analyze an observational study or conduct a randomized trial. Nevertheless, the traditional tools of population health inquiry that we use to make sense of empirical observations (observational studies, randomized trials, natural experiments, and the analytical approaches associated with them) will still be useful in interrogating aspects of systems. The problem arises when we reify these approaches so that they are interpreted as accurate and full representations of reality rather than simplifications that can sometimes be useful in understanding some aspects of how the world works. Moreover, information from these "reductionist" approaches will still be necessary to inform dynamic conceptual models and to parameterize and validate formal simulation models.

As noted by Galea, context dependency is certainly a hallmark of many of the phenomena we study and, indeed, a feature of the world itself! Our job as scientists is to specify how that context dependency works so that we can obtain knowledge that is generalizable to other contexts. Otherwise our work is reduced to descrip- tion of specific cases, which may be interesting but will not provide the generalizable knowledge we need to identify useful policies and interventions. Our task is to enhance understanding of the key elements and drivers of the systems that generate health in cities, and for this we need to specify and articulate which context dependencies are important and how they operate. The nature of our task requires us to combine systems thinking in the broad and conceptual sense with a range of tools and analytical approaches, including formal systems simulation modeling, as well as other qualitative and quantitative ways of interrogating the reality we seek to change. This will ensure that the empirical information we obtain is placed in context and its implications fully understood, and also that the systems (both conceptual and simulations) models we develop go beyond speculation and are informed by and granded in reality. 